\title{
Polygalaceae endémicas del Perú
}

\author{
Blanca León ${ }^{1,2}$
}

${ }^{1}$ Museo de Historia Natural, Av. Arenales 1256, Aptdo. 14-0434, Lima 14, Perú

2 Plant Resources Center, University of Texas at Austin, Austin TX 78712 EE.UU.

blanca.leon@mail.utexas.edu

\section{Resumen}

La familia Polygalaceae es reconocida en el Perú por presentar seis géneros y 98 especies (Brako \& Zarucchi, 1993; Ulloa Ulloa et al., 2004), principalmente arbustos. En este trabajo reconocemos 46 endemismos en tres géneros. El género más rico en especies es Monnina. Los taxones endémicos se encuentran principalmente en los Bosques Muy Húmedos Montanos, Mesoandina y Bosques Muy Húmedos Premontanos, entre los 600 y 3500 m de altitud. Se aplicaron las categorías y criterios de la UICN a 19 especies. Aparentemente, sólo ocho taxones endémicos se encuentran representados dentro del Sistema Nacional de Áreas Naturales Protegidas por el Estado.

Palabras claves: Polygalaceae, Monnina, Perú, endemismo, plantas endémicas.

\section{Abstract}

The Polygalaceae are represented in Peru by six genera and 98 species (Brako \& Zarucchi, 1993; Ulloa Ulloa et al., 2004), mostly shrubs. Here we recognize 46 endemic taxa in three genera. Monnina is the genus with the largest number of endemic species. Endemic Polygalaceae are found mainly in Very Humid Montane Forests, Mesoandean and Very Humid Premontane Forests regions, between 600 and 3550 m elevation. We applied IUCN categories and criteria to 19 species. Apparently, only eight species have been recorded within Peru's protected areas system.

Keywords: Polygalaceae, Monnina, Peru, endemism, endemic plants.

\section{Monnina acutifolia Chodat}

\section{DD}

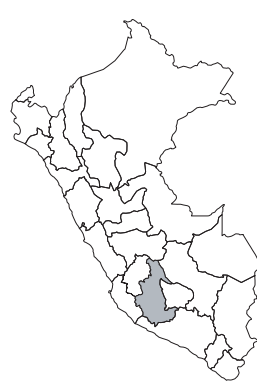

Publicación: Bull. Soc. Bot. Geneve ser. 2, 25: 206. 1934.

Colección tipo: E.P. Killip \& A.C. Smith 22448

Herbarios: F, NY, US.

Nombre común: Desconocido.

Registro departamental: AY.

Regiones Ecológicas: BMHP; $1000 \mathrm{~m}$.

SINANPE: Sin registro.

Herbarios peruanos: Ninguno.

Observaciones: Arbusto descrito de una planta recolectada en 1929, de la cuenca del Apurímac. Se desconoce el estado actual de sus poblaciones.

\section{Monnina amplibracteata Ferreyra}

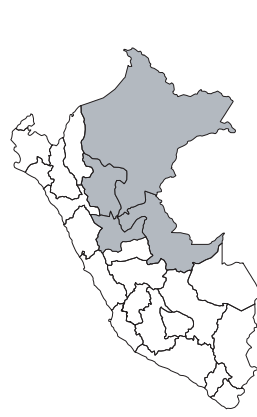

\section{DD}

Publicación: Publ. Mus. Hist. Nat. «Javier Prado» 1(1): 4—6, lám. 2. 1948.

Colección tipo: R. Ferreyra 984

Herbarios: ; USM.

Nombre común: Desconocido.

Registro departamental: HU, LO, SM, UC.

Regiones Ecológicas: BMHM, BMHP; $1130-1700 \mathrm{~m}$.

SINANPE: Sin registro.

Herbarios peruanos: HAO (1), USM (holotipo citado+5).

Observaciones: Arbusto conocido de varias localidades en el centro del país. El ejemplar tipo proviene de una localidad en el límite entre las cuencas del Huallaga y del Aguaytía, al sur del Parque Nacional Cordillera Azul. Se desconoce el estado actual de sus poblaciones.

\section{Monnina andina Chodat}

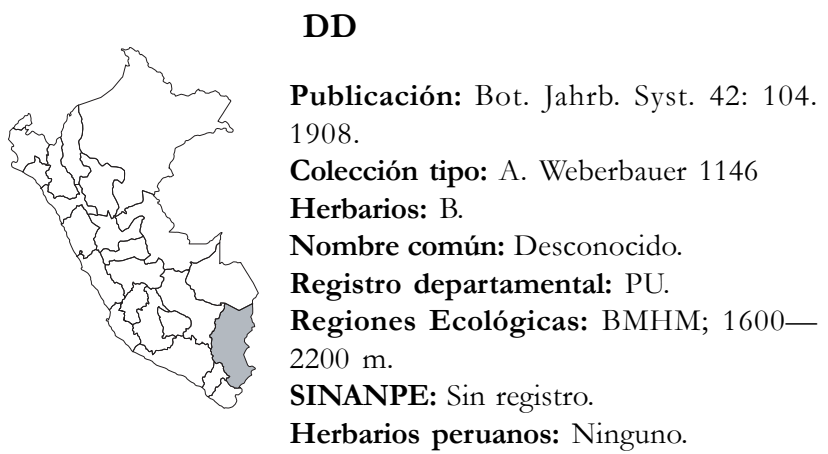

Observaciones: Arbusto recolectado en 1902 de la cuenca de un tributario del Inambari. Se desconoce el estado actual de sus poblaciones.

\section{Monnina callimorpha Chodat}

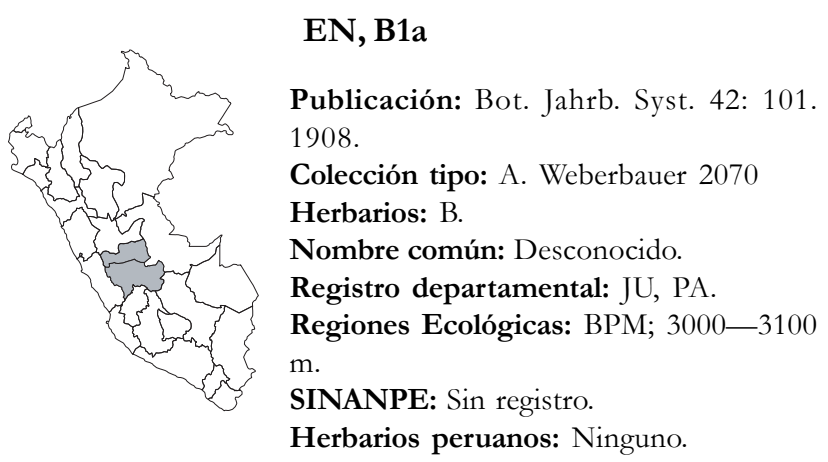

Observaciones: Especie arbustiva, conocida de las cuencas del Tulumayo y Pozuzo. Fue descrita de una planta recolectada en 1903, en Huacapistana, localidad que alberga varios otros endemismos; desafortunadamente, sus ambientes naturales están afectados por el ser humano y no reciben protección alguna. 


\section{Monnina canescens Ferreyra}

\section{DD}

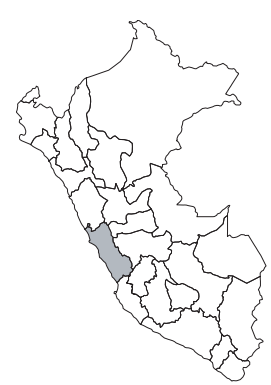

Publicación: J. Arnold Arbor. 27: 148. 1946. Colección tipo: F.W. Pennell 14376

Herbarios: $\mathrm{PH}$.

Nombre común: Desconocido.

Registro departamental: LI.

Regiones Ecológicas: Sin datos; altitud desconocida.

SINANPE: Sin registro.

Herbarios peruanos: Ninguno.

Observaciones: Especie arbustiva, descrita de una planta recolectada en la década de 1940, de la cuenca del Chillón, en la vertiente del Pacífico. La localidad original, cerca de Obrajillo, alberga otros endemismos. Se desconoce el estado actual de sus poblaciones

\section{Monnina clarkeana Chodat}

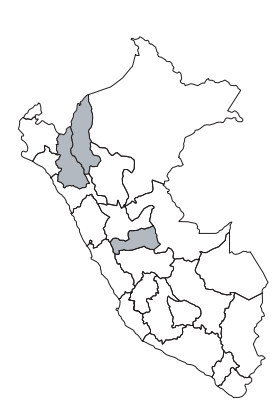

\section{DD}

Publicación: Bull. Herb. Boissier 4: 246. 1896. Colección tipo: A. Mathews 1192

Herbarios: K.

Nombre común: Desconocido.

Registro departamental: AM, CA, PA.

Regiones Ecológicas: Sin datos; altitud desconocida.

SINANPE: Sin registro.

Herbarios peruanos: Ninguno.

Observaciones: Arbusto descrito de una planta recolectada en el siglo XIX en el nororiente del país. Se desconoce detalles de la localidad exacta y el estado actual de sus poblaciones.

\section{Monnina conferta Ruiz \& Pav.}

\section{LC}

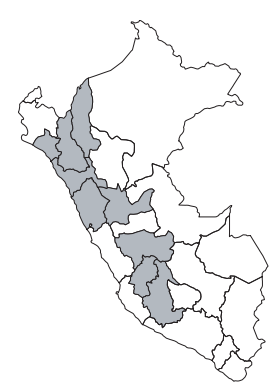

Publicación: Syst. Veg. Fl. Peruv. Chil. 173. 1798.

Colección tipo: Lagasca 56

Herbarios: MA.

Nombre común: Malmal.

Registro departamental: AM, AN, AY, CA, HU, HV, JU, LA, LL.

Regiones Ecológicas: MA, PAR; 3300$3950 \mathrm{~m}$.

SINANPE: PNH

Herbarios peruanos: CPUN (7), HAO (2), HUT (1).

Observaciones: Arbusto conocido de varias localidades, en valles interandinos de ambas vertientes y en zonas paramunas del norte del país. Esta especie se conoce de las cuencas del Santa, Marañón, Apurímac y Mantaro.

\section{Monnina confusa Ferreyra}

\section{DD}

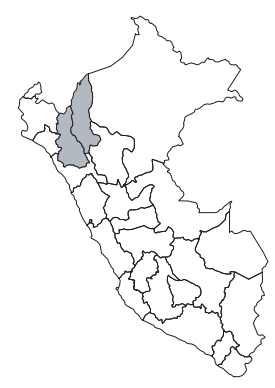

Publicación: Publ. Mus. Hist. Nat. «Javier Prado», Ser. B, Bot. 14: 2-4. 1963.

Colección tipo: J.J. Wurdack 1701

Herbarios: US; USM.

Nombre común: Desconocido.

Registro departamental: AM, CA.

Regiones Ecológicas: MA, PAR; 3000$3550 \mathrm{~m}$.

SINANPE: Sin registro.

Herbarios peruanos: CPUN (1), HAO (1), USM (holotipo citado+1).
Observaciones: Arbusto conocido de ambientes paramunos en el norte del país. Esta especie fue descrita de una planta recolectada en 1962, de la cuenca del Utcubamba. Se desconoce el estado actual de sus poblaciones

\section{Monnina densecomata Chodat}

\section{DD}

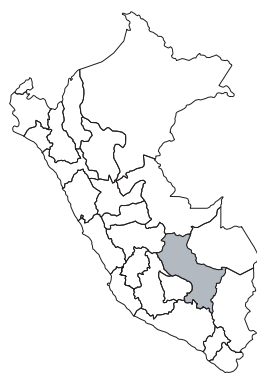

Publicación: Bull. Soc. Bot. Geneve ser. 2, 25: 209. 1934

Colección tipo: F.W. Pennell 13821

Herbarios: $\mathrm{PH}$.

Nombre común: Desconocido.

Registro departamental: CU.

Regiones Ecológicas: PSH, BPM; 3800 $\mathrm{m}$.

SINANPE: PNM

Herbarios peruanos: Ninguno.

Observaciones: Especie arbustiva descrita de una planta recolectada en la década de 1940, de los fragmentos de bosque pluvial en el límite occidental del Parque Nacional Manu. Se desconoce el estado actual de sus poblaciones

\section{Monnina divaristachya Ferreyra}

\section{DD}

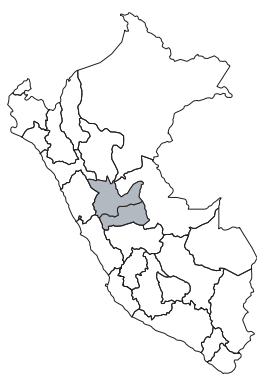

Publicación: J. Arnold Arbor. 27: 149. 1946.

Colección tipo: E.P. Killip \& A.C. Smith 25778

Herbarios: US.

Nombre común: Desconocido.

Registro departamental: HU, PA.

Regiones Ecológicas: BPM, BMHM;

1600-3200 m.

SINANPE: PNYC

Herbarios peruanos: USM (16).

Observaciones: Esta especie arbustiva se conoce de varias localidades en las cuencas del Pozuzo y del Huallaga. El ejemplar tipo fue recolectado en el antiguo camino de arrieros que unía el valle de Chanchamayo con la cuenca del Pichis. Se desconoce el estado actual de sus poblaciones

\section{Monnina filifolia Chodat}

\section{DD}

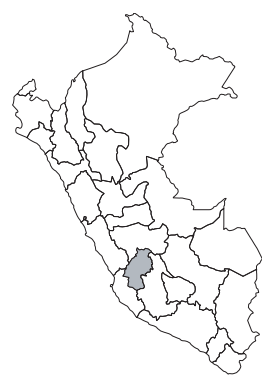

Publicación: Bull. Soc. Bot. Geneve ser. 2, 25: 198. 1934.

Colección tipo: A. Weberbauer 6454

Herbarios: F; MOL!

Nombre común: Desconocido.

Registro departamental: HV.

Regiones Ecológicas: MDE; 1800—2200 $\mathrm{m}$.

SINANPE: Sin registro.

Herbarios peruanos: MOL (isotipo).

Observaciones: Este arbusto es conocido de unas pocas localidades en la cuenca del Mantaro. El ejemplar tipo fue recolectado en 1913, de ambientes semixéricos. Se desconoce el estado actual de sus poblaciones 


\section{Monnina gaudroniana Ferreyra}

DD

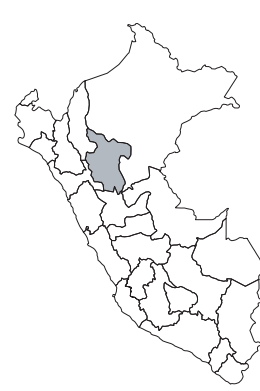

Publicación: Publ. Mus. Hist. Nat. «Javier Prado», Ser. B, Bot. 9: 5. 1955.

Colección tipo: G. Klug 3496

Herbarios: US; USM.

Nombre común: Desconocido.

Registro departamental: SM.

Regiones Ecológicas: BMHM; $1200-$ $1600 \mathrm{~m}$.

SINANPE: Sin registro.

Herbarios peruanos: USM (holotipo citado).

Observaciones: Arbusto descrito de una planta recolectada en 1943, de la cuenca del Mayo. Se desconoce el estado actual de sus poblaciones

\section{Monnina glabrifolia Ferreyra}

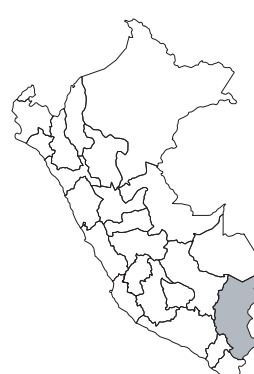

DD

Publicación: J. Arnold Arbor. 27: 142. 1946. Colección tipo: R.D. Metcalf 30661 Herbarios: UC.

Nombre común: Desconocido.

Registro departamental: PU.

Regiones Ecológicas: BMHM; $1900 \mathrm{~m}$.

SINANPE: Sin registro.

Herbarios peruanos: Ninguno.

Observaciones: Especie arbustiva, recolectada en 1942, en la cuenca del San Gabán. Se desconoce el estado actual de sus poblaciones

\section{Monnina herrerae Ferreyra}

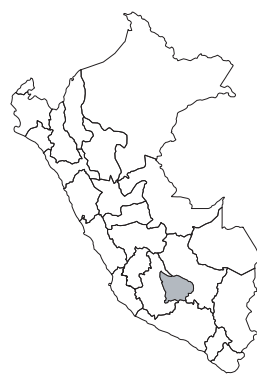

Publicación: J. Arnold Arbor. 27: 165. 1946.

Colección tipo: A. Weberbauer 5864

Herbarios: GH.

Nombre común: Desconocido.

Registro departamental: AP.

Regiones Ecológicas: Sin datos; $3400 \mathrm{~m}$.

SINANPE: Sin registro.

Herbarios peruanos: Ninguno.

Observaciones: Este taxón fue considerado por Brako \& Zarucchi (1993) como un endemismo; sin embargo, no ha sido posible evaluarlo, ni asignarle una categoría.

\section{Monnina hirtella Ferreyra}

DD

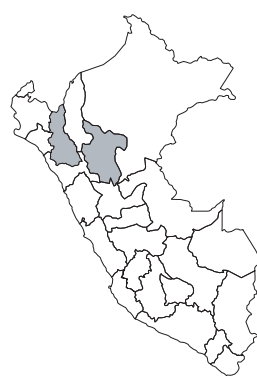

Publicación: J. Arnold Arbor. 27: 158. 1946.

Colección tipo: G. Klug 3337

Herbarios: US.

Nombre común: Desconocido.

Registro departamental: CA, SM.

Regiones Ecológicas: BMHM, BMHP; $1100-2800 \mathrm{~m}$.

SINANPE: Sin registro.

Herbarios peruanos: HAO (2).

Observaciones: Arbusto descrito de un planta recolectada en1933, de la cuenca del Mayo; pero otras poblaciones son conocidas de la cuenca del Huayllabamba. Se desconoce el estado actual de sus poblaciones
16. Monnina huallagensis Chodat var. huallagensis

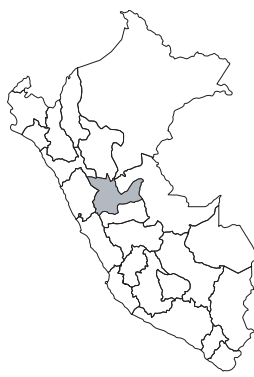

Publicación:

Colección tipo: A. Weberbauer 6805

Herbarios: G; MOL!

Nombre común: Desconocido.

Registro departamental: HU.

Regiones Ecológicas: BMHM; 1500$2100 \mathrm{~m}$.

SINANPE: Sin registro.

Herbarios peruanos: MOL (isotipo).

Observaciones: Arbusto descrito de una planta recolectada en 1913, de la cuenca del Huallaga. No ha sido posible evaluarlo, ni asignarle una categoría.

\section{Monnina huallagensis Chodat var. pachyphylla Chodat}

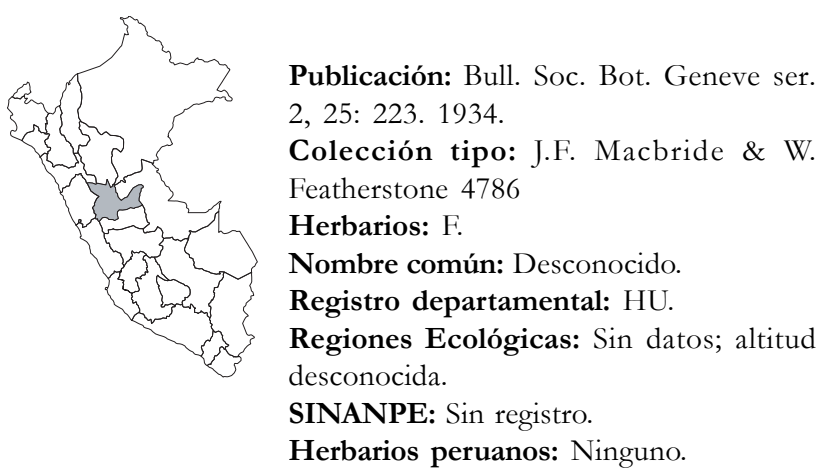

Observaciones: Este taxón fue considerado por Brako \& Zarucchi (1993) como un endemismo; sin embargo, no ha sido posible evaluarlo, ni asignarle una categoría.

\section{Monnina longibracteata Chodat var. longibracteata}

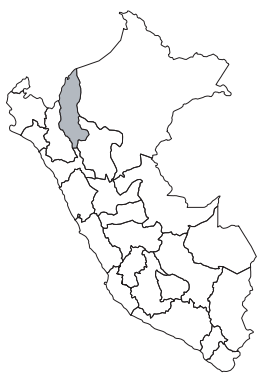

Publicación:

Colección tipo: A. Mathews 2075

Herbarios: $\mathrm{K}$

Nombre común: Desconocido.

Registro departamental: AM.

Regiones Ecológicas: Sin datos; altitud desconocida.

SINANPE: Sin registro.

Herbarios peruanos: Ninguno.

Observaciones: Arbusto descrito de una planta recolectada en el siglo XIX de procedencia exacta desconocida. No ha sido posible evaluarlo, ni asignarle una categoría.

\section{Monnina macbridei Chodat}

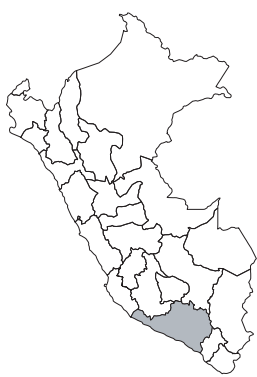

Publicación: Bull. Soc. Bot. Geneve ser. 2, 25: 199. 1934.

Colección tipo: F.W. Pennell 13167

Herbarios: $\mathrm{PH}$.

Nombre común: Desconocido.

Registro departamental: AR.

Regiones Ecológicas: MA; 2100—3500 m.

SINANPE: Sin registro.

Herbarios peruanos: Ninguno.

Observaciones: Este taxón fue considerado por Brako \& Zarucchi (1993) como un endemismo; sin embargo, no ha sido posible evaluarlo, ni asignarle una categoría. 


\section{Monnina macrosepala Chodat var. latifolia Chodat}

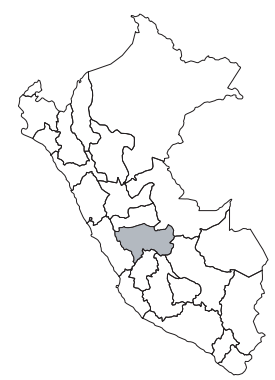

Publicación: Bull. Soc. Bot. Geneve ser. 2, 25: 219. 1934.

Colección tipo: J.F. Macbride \& W. Featherstone 5410

Herbarios: F.

Nombre común: Desconocido,

Registro departamental: JU.

Regiones Ecológicas: BMHP; $600 \mathrm{~m}$.

SINANPE: Sin registro.

Herbarios peruanos: Ninguno.

Observaciones: Taxón arbustivo descrito de una planta recolectada en 1923 de la cuenca del Tulumayo. No ha sido posible evaluarlo, ni asignarle una categoría.

\section{Monnina macrosepala Chodat var. macrosepala}

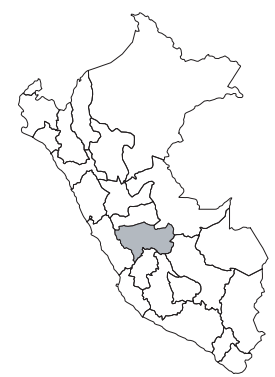

Publicación:

Colección tipo: C.O. Schunke 487

Herbarios: F.

Nombre común: Desconocido.

Registro departamental: JU.

Regiones Ecológicas: BMHP; $600 \mathrm{~m}$.

SINANPE: Sin registro.

Herbarios peruanos: Ninguno.

Observaciones: Este taxón fue considerado por Brako \& Zarucchi (1993) como un endemismo; sin embargo, no ha sido posible evaluarlo, ni asignarle una categoría.

\section{Monnina macrostachya Ruiz \& Pav.}

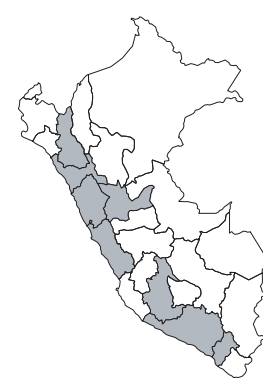

Publicación: Syst. Veg. Fl. Peruv. Chil. 173-174. 1798.

Colección tipo: H. Ruiz \& J. Pavón s.n.

Herbarios: MA.

Nombre común: Desconocido.

Registro departamental: AN, AR, AY, CA, HU, LI, LL, MO.

Regiones Ecológicas: DST, MA; 300$3200 \mathrm{~m}$.

SINANPE: Sin registro.

Herbarios peruanos: HUT (2)?, USM.

Observaciones: Especie arbustiva conocida de varias localidades en la vertiente del Pacífico. El ejemplar tipo fue recolectado en el siglo XVIII, de una localidad no precisada. No ha sido posible evaluarla, ni asignarle una categoría.

\section{Monnina mathusiana Chodat}

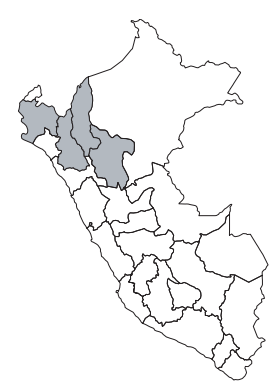

Publicación: Bull. Herb. Boissier 3: 134. 1895. Colección tipo: A. Mathews 1190 Herbarios: W.

Nombre común: Desconocido.

Registro departamental: AM, CA, SM.

Regiones Ecológicas: BMHM; 1400$2350 \mathrm{~m}$.

SINANPE: PNC

Herbarios peruanos: CPUN (3), HAO (1).

Observaciones: Planta escandente, conocida de varias localidades en el nor- oriente del país. No ha sido posible evaluarlo, ni asignarle una categoría.

\section{Monnina membranifolia Ferreyra}

\section{DD}

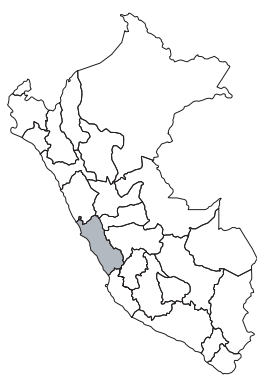

Publicación: Publ. Mus. Hist. Nat. «Javier Prado» 1(1): 2—4, lám. 1. 1948.

Colección tipo: R. Ferreyra 700

Herbarios: ; USM.

Nombre común: Desconocido.

Registro departamental: LI.

Regiones Ecológicas: MA; 3200—3300 m. SINANPE: Sin registro.

Herbarios peruanos: USM (holotipo citado+5).

Observaciones: Especie arbustiva descrita de una planta recolectada en 1946, de la cuenca del Rímac. Ejemplares adicionales provienen de la misma cuenca, de matorrales y fragmentos de bosque perennifolio de la vertiente del Pacífico. Se desconoce el estado actual de sus poblaciones.

\section{Monnina menthoides Chodat}

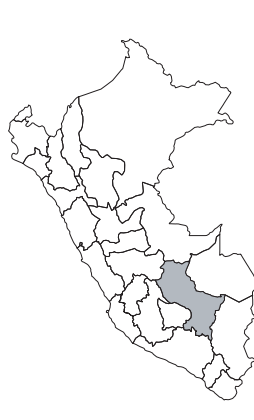

\section{DD}

Publicación: Bull. Soc. Bot. Geneve ser. 2, 25: 219. 1934.

Colección tipo: A. Weberbauer 7786

Herbarios: G.

Nombre común: Desconocido.

Registro departamental: CU.

Regiones Ecológicas: BMHM; 2900$3200 \mathrm{~m}$.

SINANPE: Sin registro.

Herbarios peruanos: Ninguno.

Observaciones: Especie arbustiva descrita de una planta recolectada en 1929, de la cuenca del Marcapata. Se desconoce el estado actual de sus poblaciones.

\section{Monnina ovata Ferreyra}

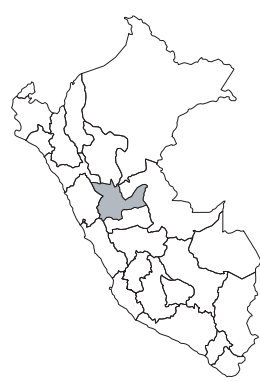

Publicación: J. Arnold Arbor. 27: 151. 1946. Colección tipo: J.F. Macbride \& W. Featherstone 4493

Herbarios: F, US.

Nombre común: Desconocido.

Registro departamental: HU.

Regiones Ecológicas: BPM; $2700 \mathrm{~m}$.

SINANPE: Sin registro.

Herbarios peruanos: Ninguno.

Observaciones: Arbusto descrito de una planta recolectada en 1923, de la cuenca del Huallaga. No ha sido posible evaluarlo, ni asignarle una categoría.

\section{Monnina pachycoma Chodat}

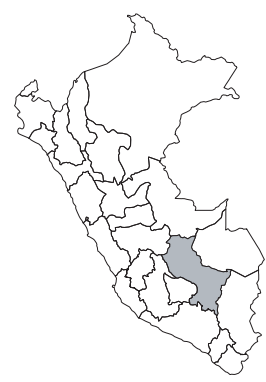

Publicación: Bull. Soc. Bot. Geneve ser. 2, 25: 220. 1934.

Colección tipo: F.W. Pennell 13834

Herbarios: G, PH.

Nombre común: Desconocido.

Registro departamental: CU.

Regiones Ecológicas: PSH, BPM; 3600 m.

SINANPE: PNM

Herbarios peruanos: Ninguno. 
Observaciones: Arbusto descrito de una planta recolectada en 1934, de una localidad hoy en lado occidental del Parque Nacional Manu. No ha sido posible evaluarlo, ni asignarle una categoría.

\section{Monnina pavoni Chodat}

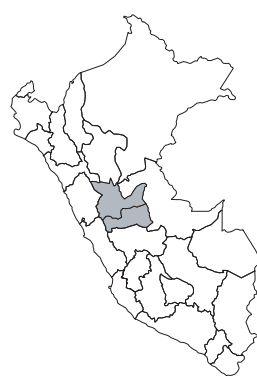

Publicación: Bull. Herb. Boissier 3: 132. 1895.

Colección tipo: H. Ruiz \& J. Pavón s.n. Herbarios: MA.

Nombre común: Desconocido.

Registro departamental: HU, PA.

Regiones Ecológicas: BMHM; altitud desconocida.

SINANPE: Sin registro.

Herbarios peruanos: Ninguno.

Observaciones: Este taxón fue considerado por Brako \& Zarucch (1993) como un endemismo; sin embargo, no ha sido posible evaluarlo, ni asignarle una categoría.

\section{Monnina polygonoides Chodat}

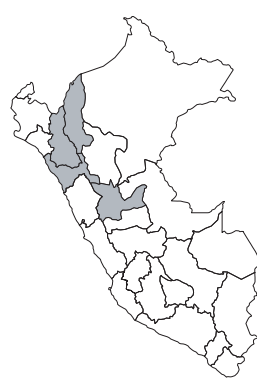

Publicación: Bull. Soc. Bot. Geneve ser. 2, 25: 200. 1934

Colección tipo: J.F. Macbride 3181

Herbarios: F, GH, NY, US.

Nombre común: Desconocido.

Registro departamental: AM, CA, HU, LL. Regiones Ecológicas: MA; 2100—2700 m.

SINANPE: Sin registro,

Herbarios peruanos: Ninguno.

Observaciones: Este taxón fue considerado por Brako \& Zarucchi (1993) como un endemismo. Eriksen (1993) transfirió esta especie al género Pteromonnina. No ha sido posible evaluarlo, ni asignarle una categoría.

\section{Monnina polystachya Ruiz \& Pav.}

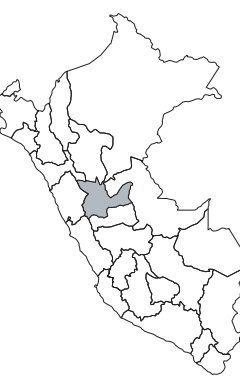

Publicación: Syst. Veg. Fl. Peruv. Chil. 171-172. 1798.

Colección tipo: H. Ruiz s.n.

Herbarios: G-DC.

Nombre común: Desconocido.

Registro departamental: HU.

Regiones Ecológicas: BMHM; $3000 \mathrm{~m}$.

SINANPE: Sin registro.

Herbarios peruanos: Ninguno.

Observaciones: Este taxón fue considerado por Brako \& Zarucchi (1993) como un endemismo; sin embargo, no ha sido posible evaluarlo, ni asignarle una categoría.

\section{Monnina pseudopolystachya Chodat}

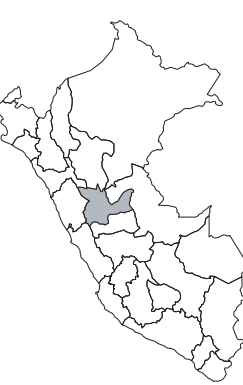

Publicación: Bull. Soc. Bot. Geneve ser. 2, 25: 217. 1934

Colección tipo: J.F. Macbride 4317

Herbarios: F, US

Nombre común: Desconocido.

Registro departamental: HU.

Regiones Ecológicas: BMHM; $2400 \mathrm{~m}$.

SINANPE: Sin registro.

Herbarios peruanos: Ninguno
Observaciones: Este taxón fue considerado por Brako \& Zarucchi (1993) como un endemismo; sin embargo, no ha sido posible evaluarlo, ni asignarle una categoría.

\section{Monnina pseudosalicifolia Ferreyra}

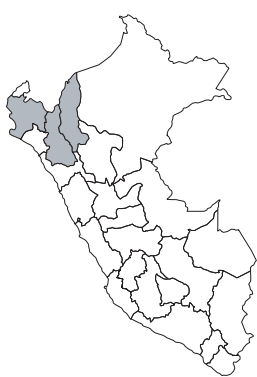

Publicación: J. Arnold Arbor. 27: 145. 1946.

Colección tipo: A. Weberbauer 6055

Herbarios: US

Nombre común: Desconocido.

Registro departamental: AM, CA, PI.

Regiones Ecológicas: BMHM; $2500 \mathrm{~m}$.

SINANPE: PNC

Herbarios peruanos: CPUN (1).

Observaciones: Este taxón fue considerado por Brako \& Zarucchi (1993) como un endemismo; sin embargo, no ha sido posible evaluarlo, ni asignarle una categoría.

\section{Monnina ramosa I.M. Johnst.}

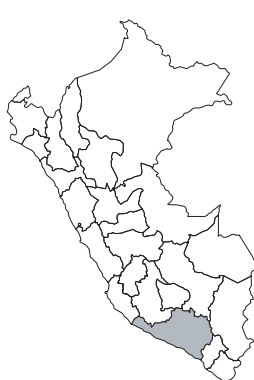

Publicación: Contr. Gray Herb. 70: 77. 1924

Colección tipo: F.E. Hinkley \& Hinkley 13

Herbarios: US.

Nombre común: Desconocido.

Registro departamental: AR.

Regiones Ecológicas: MA; 3300 m.

SINANPE: Sin registro.

Herbarios peruanos: Ninguno.

Observaciones: Especie subarbustiva, conocida solamente del sur del país. Fue recolectada en 1920, de ambientes xéricos en una planicie con arena volcánica. No ha sido posible evaluarla, ni asignarle una categoría.

\section{Monnina salicifolia Ruiz \& Pav. var. pilostylis Ferreyra}

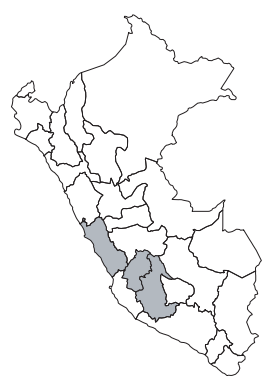

Publicación: J. Arnold Arbor. 27(2): 158. 1946. Colección tipo: E.P. Killip \& A.C. Smith 21569

Herbarios: US.

Nombre común: Desconocido.

Registro departamental: AY, HV, LI.

Regiones Ecológicas: MA; altitud desconocida.

SINANPE: Sin registro.

Herbarios peruanos: Ninguno.

Observaciones: Este taxón fue considerado por Brako \& Zarucchi (1993) como un endemismo; sin embargo, no ha sido posible evaluarlo, ni asignarle una categoría.

\section{Monnina sanmarcosana Ferreyra}

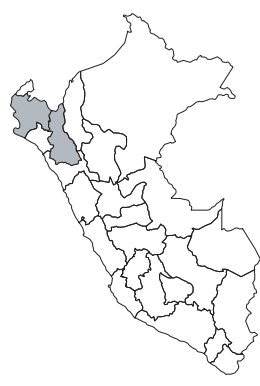

Publicación: Publ. Mus. Hist. Nat. «Javier Prado», Ser B, Bot. 3: 6-8. 1951.

Colección tipo: J. Soukup 3857

Herbarios: US; USM.

Nombre común: Desconocido.

Registro departamental: CA, PI.

Regiones Ecológicas: Sin datos; 1800 m. SINANPE: Sin registro.

Herbarios peruanos: USM (isotipo citado). 
Observaciones: Este taxón fue considerado por Brako \& Zarucchi (1993) como un endemismo; sin embargo, no ha sido posible evaluarlo, ni asignarle una categoría.

\section{Monnina soukupiana Ferreyra}

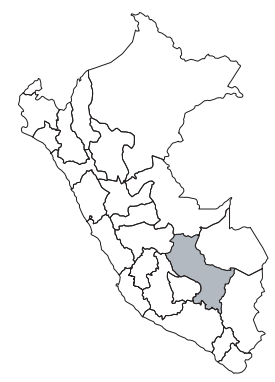

Publicación: Publ. Mus. Hist. Nat. «Javier Prado», Ser. B, Bot. 9: 2-4. 1955.

Colección tipo: F. Woytkowski 281

Herbarios: ; USM.

Nombre común: Desconocido.

Registro departamental: CU.

Regiones Ecológicas: Sin datos; altitud desconocida.

SINANPE: Sin registro.

Herbarios peruanos: USM (holotipo citado).

Observaciones: Este taxón fue considerado por Brako \& Zarucchi (1993) como un endemismo; sin embargo, no ha sido posible evaluarlo, ni asignarle una categoría.

\section{Monnina tomentella Chodat}

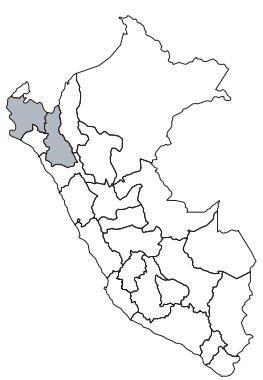

Publicación: Bull. Soc. Bot. Geneve ser. 2, 25: 210. 1934.

Colección tipo: A. Weberbauer 6189

Herbarios: F, GH.

Nombre común: May-mal.

Registro departamental: CA, PI.

Regiones Ecológicas: MA; 3000—3150 m.

SINANPE: Sin registro.

Herbarios peruanos: USM (3).

Observaciones: Este taxón fue considerado por Brako \& Zarucchi (1993) como un endemismo; sin embargo, no ha sido posible evaluarlo, ni asignarle una categoría.

\section{Monnina valcarceliana Ferreyra}

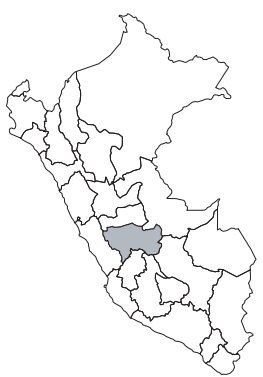

Publicación: Publ. Mus. Hist. Nat. «Javier Prado», Ser. B, Bot. 26: 6—8, t. Ia, Ib. 1973. Colección tipo: E. Cerrate \& R. Ferreyra 5581 Herbarios: ; USM.

Nombre común: Desconocido.

Registro departamental: JU.

Regiones Ecológicas: BMHM; $3200 \mathrm{~m}$. SINANPE: Sin registro.

Herbarios peruanos: USM (holotipo).

Observaciones: Este taxón fue considerado por Brako \& Zarucchi (1993) como un endemismo; sin embargo, no ha sido posible evaluarlo, ni asignarle una categoría.

\section{Monnina vargasii Ferreyra}

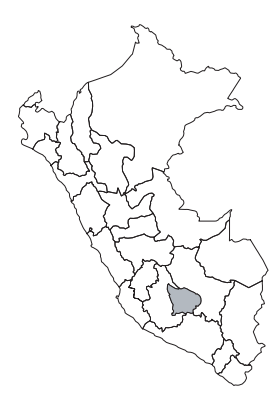

\section{EN, B1a}

Publicación: J. Arnold Arbor. 27: 162. 1946.

Colección tipo: C. Vargas C. 771

Herbarios: F, GH; USM (fr)!.

Nombre común: Cola de ratón.

Registro departamental: AP.

Regiones Ecológicas: MA; 2200—3400 m.

SINANPE: SNA

Herbarios peruanos: USM (isotipofragmento+2).
Observaciones: Arbusto conocido de las cuencas del Urubamba y Pachachaca. La colección original, recolectada en 1938, proviene de una localidad hoy en un área protegida, Santuario Nacional Ampay. Amenazas están vinculadas a la deforestación, tala y extracción de flora.

\section{Monnina vitis-idaea Chodat}

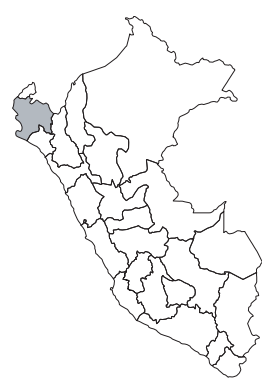

Publicación: Bull. Soc. Bot. Geneve ser. 2, 25: 208. 1934

Colección tipo: A. Weberbauer 6129

Herbarios: F, GH.

Nombre común: Desconocido.

Registro departamental: PI.

Regiones Ecológicas: Sin datos; altitud desconocida.

SINANPE: Sin registro.

Herbarios peruanos: Ninguno.

Observaciones: Este taxón fue considerado por Brako \& Zarucchi (1993) como un endemismo; sin embargo, no ha sido posible evaluarlo, ni asignarle una categoría.

\section{Monnina woytkowski Ferreyra}

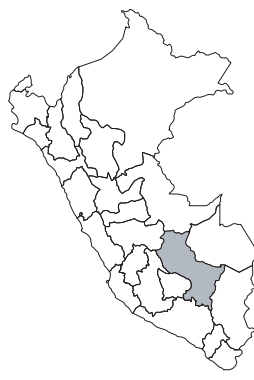

Publicación: Publ. Mus. Hist. Nat. «Javier Prado», Ser. B, Bot. 9: 7—9. 1955.

Colección tipo: F. Woytkowski 461

Herbarios: ; USM.

Nombre común: Desconocido.

Registro departamental: $\mathrm{CU}$.

Regiones Ecológicas: BMHM; $2600 \mathrm{~m}$.

SINANPE: Sin registro.

Herbarios peruanos: USM (holotipo).

Observaciones: Este taxón fue considerado por Brako \& Zarucchi (1993) como un endemismo; sin embargo, no ha sido posible evaluarlo, ni asignarle una categoría.

\section{Polygala anatina Chodat}

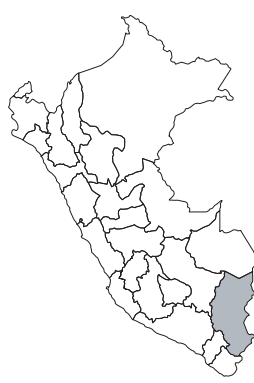

Publicación: Bot. Jahrb. Syst. 42: 98. 1908. Colección tipo: A. Weberbauer 1072

Herbarios: B.

Nombre común: Desconocido.

Registro departamental: PU.

Regiones Ecológicas: BMHP; $1500 \mathrm{~m}$.

SINANPE: Sin registro.

Herbarios peruanos: Ninguno.

Observaciones: Este taxón fue considerado por Brako \& Zarucchi (1993) como un endemismo; sin embargo, no ha sido posible evaluarlo, ni asignarle una categoría.

\section{Polygala coridifolia C. Pres1}

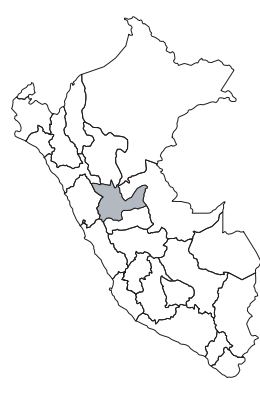

Publicación: Reliq. Haenk. 2(2): 99. 1835. Colección tipo: T. Haenke s.n.

Herbarios: PR.

Nombre común: Chinchinia.

Registro departamental: HU.

Regiones Ecológicas: Sin datos; altitud desconocida.

SINANPE: Sin registro.

Herbarios peruanos: Ninguno. 
Observaciones: Este taxón fue considerado por Brako \& Zarucchi (1993) como un endemismo; sin embargo, no ha sido posible evaluarlo, ni asignarle una categoría.

\section{Polygala pearcei A.W. Benn.}

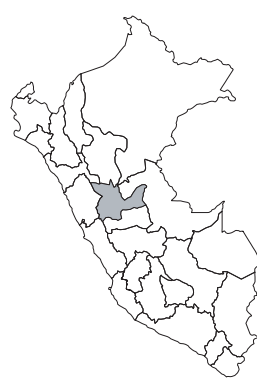

Publicación: J. Bot. 17: 201. 1879 Colección tipo: R.W. Pearce s.n. Herbarios: K.

Nombre común: Desconocido.

Registro departamental: HU.

Regiones Ecológicas: BMHM; 2100$2400 \mathrm{~m}$.

SINANPE: Sin registro.

Herbarios peruanos: Ninguno.

Observaciones: Arbusto descrito de una planta recolectada en el siglo XIX, en la cuenca alta del Huallaga. No ha sido posible evaluar esta especie, ni asignarle una categoría.

\section{Polygala weberbaueri Chodat}

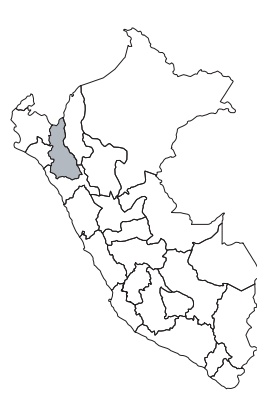

\section{VU, B1a}

Publicación: Bot. Jahrb. Syst. 42: 97. 1908. Colección tipo: A. Weberbauer 4038

Herbarios: B; MOL!.

Nombre común: Desconocido.

Registro departamental: CA.

Regiones Ecológicas: MA; 1050—3000 $\mathrm{m}$

SINANPE: Sin registro.

Herbarios peruanos: CPUN (8), MOL (isotipo).

Observaciones: Hierba que se conoce solamente de Cajamarca, de zonas xéricas, en la cuenca del Marañón. Al parecer, depende de las lluvias estacionales. Amenazas a las poblaciones provendrían de la actividad minera.

\section{Securidaca dolod B. Walln.}

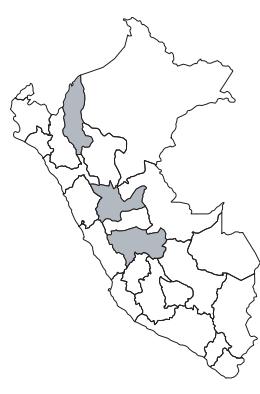

VU, B1a

Publicación: Ann. Naturhist. Mus. Wien 100B: 709, f. 1-4. 1998.

Colección tipo: B. Wallnöfer 11-11688

Herbarios: G, NY, LZ, W; USM.

Nombre común: Desconocido.

Registro departamental: $\mathrm{AM}, \mathrm{HU}, \mathrm{JU}$.

Regiones Ecológicas: BMHP; $800 \mathrm{~m}$.

SINANPE: RCS

Herbarios peruanos: USM (isotipo citado).

Observaciones: Liana descrita de una planta recolectada en 1988, de la cuenca del Pachitea. Se conoce tambiénde poblaciones en las cuencas del Imaza y Tulumayo. En la localidad original, la deforestación asociada a la ampliación agrícola podría ser de preocupación. 